\title{
O Universo teen de Gossip Girl \\ em Língua Portuguesa: uma proposta de ensino das competências tradutórias para aprendizes
}

\author{
Talita Serpa \\ Universidade Estadual Paulista - Unesp/Ibilce \\ talitasrp82@gmail.com
}

Ariane Donizete Delgado Ribeiro Caldas Universidade Estadual Paulista - Unesp/Ibilce ariane.caldass@gmail.com

Paula Tavares Pinto Universidade Estadual Paulista - Unesp/Ibilce paulapintounesp@gmail.com

\section{Resumo}

Os objetivos de nossa proposta são: 1) elencar expressões idiomáticas formuladas a partir das palavras de maior frequência e chavicidade presentes no corpus composto pela legenda da série televisiva Gossip Girl em inglês; 2) analisar as opções tradutórias adotadas em português para esse conjunto léxico; e 3) converter os dados em uma proposta de atividades para o desenvolvimento das competências tradutórias, nos moldes de Hurtado Albir (2000, 2001, 2005). Para tanto, nos valemos da abordagem proposta por Camargo (2005, 2007), adotando o arcabouço dos Estudos da Tradução Baseados em Corpus (BAKER, 1995, 1996, 2000), da Linguística de Corpus (BERBER SARDINHA, 2004) e da Lexicologia (XATARA, 1994, 1998). Procuramos, ainda, associar o ensino de competências tradutórias ao uso de corpora para a formação de tradutores (BERBER SARDINHA, 2010). Os resultados apontaram para o uso de explicitações e de omissões no que tange ao processo tradutório das expressões idiomáticas. No âmbito das práticas em sala de aula, notamos que o uso de jogos abordando as EIs levantadas na pesquisa conduzem a uma interpretação léxico-semântica mais ampla, bem como ao reconhecimento das habilidades necessárias para lidar com a tradução de legendas para um público jovem. 
Palavras-chave: Pedagogia da Tradução Baseada em Corpus. Linguística de Corpus. Estudos da Tradução Baseados em Corpus. Expressões Idiomáticas. Gossip Girls.

\section{Abstract}

The aims of this paper are: 1) to list idioms based on the most frequent words and keywords from a corpus of subtitles of the TV series Gossip Girl in English; 2) to analyze the translations used in Portuguese for this lexical set; and 3) to convert the data into a proposal of activities for the development of translational competencies based on the studies of Hurtado Albir (2000, 2001, 2005). We also use the Camargo's approach $(2005,2007)$, the framework of Corpus-Based Translation Studies (BAKER, 1995, 1996, 2000), Corpus Linguistics (BERBER SARDINHA, 2004) and Lexicology (XATARA, 1994, 1998). Besides that, we associate the teaching of translational competencies to use of corpora for translation training (BERBER SARDINHA, 2010). The results pointed to the use of explicitation and omission in relation to the translation process of idioms. Within the scope of practice in classroom, we observed that the use of games addressing idioms leads to a broader lexicalsemantic interpretation and to the recognition of skills required to deal with the translation of subtitles for a young audience.

KEYWORDS: Corpus-Based Translation Pedagogy. Corpus Linguistics. Corpus-Based Translation Studies. Idiomatic Expressions. Gossip Girls.

\section{Introdução}

Gossip Girl (A garota do blog) é uma série produzida para a televisão, baseada nos romances homônimos da escritora Cecily von Ziegesar. O seriado teve seus primeiros episódios lançados no ano de 2007 pela emissora americana CW (Warner Channel), totalizando 121 episódios, em 2012, quando chegou ao fim.

Por abordar o universo de jovens estudantes de uma escola de elite no Upper East Side de Manhattan em Nova Iorque, a obra tornouse amplamente conhecida entre adolescentes de todo o mundo, ganhando adaptações para diversos países, como China, Japão e Brasil.

O teor central da estória são relatos de escândalos cotidianos retratados por um blog cujo administrador é anônimo. Sendo assim, o conteúdo léxico-semântico constrói-se apoiado nos diálogos das personagens e nos textos da página da web, promovendo um ambiente 
propício para a criação e uso de gírias ${ }^{1}$ e de expressões idiomáticas (EIs) comumente utilizadas por adolescentes.

Tendo por base tal contexto, o presente trabalho busca avaliar os processos tradutórios utilizados na legendagem de cinco temporadas da série (2007 a 2011) e em suas respectivas traduções na direção inglês $\rightarrow$ português. Procuramos, primeiramente, promover a observação e descrição das EIs formadas a partir das palavras de maior frequência $^{2}$ e de maior chavicidade ${ }^{3}$ nas legendas sob a perspectiva da Linguística de Corpus (LC) (BERBER SARDINHA, 2004; BIBER et al, 1998; TOGNINI-BONELLI, 2002), notabilizando as estratégias e procedimentos comumente utilizados neste gênero textual ${ }^{4}$.

Em um segundo momento, compreendemos que os dados levantados com o uso de corpora podem ser utilizados em atividades didáticas, conforme os conceitos promulgados pelo grupo PACTE (2011, 2014) e por Hurtado Albir (1993, 2000, 2001), promovendo as competências (comunicativa, extralinguística, instrumental, psicofisiológica, estratégica e de transferência) na cultura fonte e na cultura meta.

Acreditamos que o uso de textos fonte (TFs) e textos meta (TMs) colabora no processo de ensino-aprendizagem, de modo especial no que tange a seleção vocabular realizadas por tradutores em formação. A verificação dos TMs e a investigação paralela com as

\footnotetext{
${ }^{1}$ Não abordaremos o conceito de gíria em nossa investigação.

${ }^{2}$ A frequência é uma característica típica da palavra. Aliás, a norma linguística se baseia na frequência dos usos linguísticos. Assim, a norma linguística nada mais é do que a média dos usos frequentes das palavras que são aceitas pelas comunidades dos falantes. E não é só isso. Também as mudanças linguísticas que, no decorrer da história, levam de um estado de língua a outro, advém das frequências de certos usos em detrimento de outros. (BIDERMAN, 1998 apud BERBER SARDINHA, 2004, p. 163)

3 Palavras-chave, geradas pela análise da chavicidade, são aquelas cuja frequência no corpus de estudo é estatisticamente significante se comparada à frequência da mesma palavra em um corpus de referência (corpus de língua geral pelo menos cinco vezes maior que o corpus de estudo).

${ }^{4}$ Para Bakhtin (1992) o gênero se define como "tipos relativamente estáveis de enunciados" elaborados pelas diferentes esferas de utilização da língua. Considera três elementos "básicos" que configuram um gênero discursivo: conteúdo temático, estilo e forma composicional (VERCEZE, 2008).
} 
escolhas realizadas pelos tradutores profissionais que traduziram as legendas anteriormente, podem promover um reconhecimento aprofundado e o ganho de consciência acerca do processo-produto tradutório. Com isso, os aprendizes de tradução passam a reconhecer as estruturas e os padrões dos idiomas, ampliando seus conhecimentos sobre os usos e reusos dos sistemas linguísticos.

Utilizamos, como teorização, a Pedagogia da Tradução Baseada em Corpus (LAVIOSA, 2002) bem como trabalhos de Alves (2003) e Gonçalves e Machado (2006), os quais apresentam um panorama das discussões sobre a facilitação do desenvolvimento de competências com a utilização de corpora na formação de tradutores, com foco na composição de atividades que promovam as habilidades atreladas à prática de traduzir.

\section{Os conceitos de corpus, palavra, vocábulo e expressão idiomática}

Ao considerarmos que nossa pesquisa toma como base o conceito de corpus, convém ressaltarmos que, de acordo com Biber et al (1998), a abordagem da LC:

- É empírica, analisando os padrões atuais de uso em textos naturais;

- Utiliza uma grande coleção de textos naturais baseada em princípios, conhecida como "corpus", como base para análise;

- Faz extensivo uso de computadores para análises, usando técnicas automáticas e interativas;

- Depende de ambas as técnicas de análise, quantitativa e qualitativa. ${ }^{5}$ (BIBER et al, 1998, p. 4)

5 "The essential characteristics of corpus-based analysis are:

- it is empirical, analyzing the actual patterns of use in natural texts;

- it utilizes a large and principled collection of natural texts, known as a 'corpus', as the basis for analysis;

- it makes extensive use of computers for analysis, using both automatic and interactive techniques; 
Acrescemos a esta caracterização, a acepção oferecida por Sanchez e Cantos (1996), a qual é tomada por Berber Sardinha (2004) como sendo a mais completa e específica. Sendo assim, consideramos corpus

Um conjunto de dados linguísticos (pertencentes ao uso oral ou escrito da língua, ou a ambos), sistematizados segundo determinados critérios, suficientemente extensos em amplitude e profundidade, de maneira que sejam representativos da totalidade do uso linguístico ou de algum de seus âmbitos, dispostos de tal modo que possam ser processados por computador, com a finalidade de propiciar resultados vários e úteis para a descrição e análise. (SANCHEZ; CANTOS, 1996 apud BERBER SARDINHA, 2004)

No âmbito das pesquisas em Tradução, ainda faz-se necessário reconhecer a concepção de corpus paralelo, o qual, segundo TogniniBonelli (2002) permite uma estreita "correspondência frase por frase entre os dois textos" 6 (TOGNINI-BONELLI, 2001, p. 6-7). Baker (1993, p. 238), por sua vez, explicita que corpora paralelos são "corpora de textos fonte e suas respectivas traduções" 7.

No que diz respeito à relação entre palavras e vocábulos, verificamos que o vocábulo como um modelo de realização de palavras que o representam no texto (BARBOSA, 1990, p.233). Desse modo, a palavra é uma unidade do texto e o vocábulo é uma unidade do léxico (BARROS, 2004, p.41).

No Dicionário de Linguística (DUBOIS, et. al. 1973, p.449450), encabeçado por Jean Dubois, temos a seguinte definição para palavra

(...) um elemento linguístico significativo composto de um ou mais fonemas; essa sequência é suscetível de uma transcrição escrita (ideogramática, silabaria ou alfabética)

- it depends on both quantitative and qualitative analytical techniques. [Todas as traduções serão de nossa responsabilidade].

6 “(...), sentence-by-sentence correspondence between the two texts."

${ }^{7}$ Parallel corpora, that is corpora of source texts and their translations. 
compreendida entre dois espaços em branco; ela conserva sua forma, total ou parcialmente (no caso da flexão), em seus diversos empregos sintagmáticos; a palavra denota um objeto (substantivo), uma ação ou um estado (verbo), uma qualidade (adjetivo), uma relação (preposição), etc.

Além dessa leitura, as palavras relacionam-se com os vocábulos, que são descritos como:

(....) a ocorrência de um lexema no discurso, na terminologia da estatística lexical. Como o termo lexema está reservado às unidades (virtuais) que compõem o léxico, o termo palavra a qualquer ocorrência realizada em fala, o vocábulo será a atualização de um lexema particular no discurso.

Sob este ponto de vista, o lexema é uma unidade do léxico (estoque potencial do indivíduo ou da língua), enquanto o vocábulo e a palavra são unidades do vocabulário (unidades efetivamente empregadas num determinado uso de comunicação); a palavra representa então toda unidade emitida (...) enquanto o vocábulo representa uma unidade particular emitida considerada em referência ao léxico. (DUBOIS, et. al. 1973, p.614).

No tocante às expressões idiomáticas (EIs) tomamos por base a definição de Xatara (1994, 1998), a qual nos diz que uma "expressão idiomática é uma lexia complexa indecomponível, conotativa e cristalizada em um idioma pela tradição cultural”.

\section{A Linguística de Corpus e os Estudos da Tradução baseados em corpus}

Com base nas evoluções das pesquisas com corpora dentro dos Estudos Linguísticos, a pesquisadora Mona Baker (1993, 1996, 1999, 2000) lançou mão de uma nova leitura teórico-metodológica que associou a empiricidade da LC aos princípios dos Estudos Descritivos 
da Tradução ${ }^{8}$ (TOURY, 1978; EVEN-ZOHAR, 1978). A autora eleva os textos metas (TMs) a:

[...] eventos comunicativos genuínos [que] como tais não são nem inferiores nem superiores a outros eventos comunicativos em qualquer língua. Entretanto, eles são diferentes, e a natureza dessa diferença precisa ser explorada e registrada..$^{9}$ (BAKER, 1993, p.234).

A fim de alavancar as pesquisas baseadas em seu ponto de vista, Baker desenvolveu um quadro epistemológico que abarcou os principais constituintes dos procedimentos tradutórios, de modo a observá-los de maneira reflexiva não apenas do ponto de vista formal, mas também em sua orientação social. Compreendeu, assim, a apreciação do Texto Meta em seu ambiente de interação e deu abertura para um enfoque comparativo em corpora eletrônicos. Ao contrário de outros teóricos que procuravam ressaltar valores culturais ou puramente linguísticos nos TMs, esta autora buscou elucidar a natureza do TM e do processo tradutório, ou seja, delimitar o objeto e o método de uma investigação científica independente que observasse os universais da tradução, ou seja, traços de tradução comumente utilizados por tradutores de modo geral.

\section{Corpus e ensino de tradução}

Os recursos da LC vêm sendo utilizados dentro dos princípios didáticos para o ensino de Tradução principalmente no que concerne às bases das línguas envolvidas nos processos tradutórios. Por apresentar parâmetros metodológicos e teóricos pautados nos usos de padrões de formações linguísticas, a área auxilia na verificação de recorrências de

\footnotetext{
${ }^{8}$ Os Estudos Descritivos da Tradução compreendem análises que têm por base o produto tradutório.

${ }^{9}$ Translated texts record genuine communicative events and as such are neither inferior nor superior to other communicative events in any language. They are however different, and the nature of this difference needs to be explored and recorded.
} 
elementos lexicais e gramaticais por parte dos estudantes. Para Berber Sardinha (2010, p. 304), o uso de corpora em sala de aula demonstra que

[...] a linguagem é usada de modo padronizado (isto é, de modo reconhecido como 'esperado' ou 'típico' por seus usuários), com correlações entre uso e contexto- contextos diferentes são expressos de maneiras distintas, com suas próprias probabilidades de uso, muitas vezes ajustadas de modo bastante específico [...] ao contexto social, situacional, falante, período histórico, etc. [...] Assim, por meio de uso de corpora no ensino, podemos trazer aos alunos esse sistema de modo mais claro do que com aportes de outras teorias e metodologias da linguística. (BERBER SARDINHA, 2010, p.304).

Nesse contexto, o conhecimento sobre as linguagens pode ser mediado pelo educador e o aluno passa a aprender a lidar com a análise de dados por meio da utilização das ferramentas (computacionais e teóricas) que lhe são apresentadas, de maneira a favorecer o desenvolvimento de sua autonomia durante o seu processo de aprendizagem.

Além disso, ao transformarmos os corpora paralelos em material de ensino, trazemos à baila a relação padronização-variação das linguagens no que se refere aos procedimentos tradutórios previamente adotados pelos tradutores dos TFs e TMs. Berber Sardinha corrobora tal proposição e salienta que novamente a Linguística de Corpus apresenta os instrumentos para análise de textos e de gêneros, como, por exemplo, as “(...) listas de palavras, palavraschave, segmentadores textuais, etiquetadores, etc.” (BERBER SARDINHA, 2010, p.306).

Com isso, a Pedagogia da Tradução Baseada em Corpus (LAVIOSA, 2002) proporciona novas ferramentas para os professores e favorece a compreensão de elementos linguístico-culturais que, de outra forma, seriam dificilmente trabalhados em sala.

A utilização dos recursos gerados a partir do produto dos TMs vem sendo cada vez mais enfatizada. Laviosa (2002, p. 22) observa que 
(...) a abordagem baseada em corpus tem sido desenvolvida e aplicada ao ensino de Tradução, no qual pesquisas experimentais e empíricas caminham lado a lado com programas didáticos inovadores que envolvem diretamente os estudantes na elaboração, criação, exploração $e$ desenvolvimento de corpora com o objetivo de melhorar a qualidade de suas traduções ${ }^{10}$ (LAVIOSA, 2002, p.22).

Bernardini, Stewart e Zanettin compõem um grupo de estudiosos que analisa o impacto prático da utilização de corpora na formação do tradutor, uma vez que este "(...) habilitaria os estudantes a se tornarem melhores profissionais da linguagem em um ambiente em que as facilidades computacionais para processamento textual tornaram-se regra" 11 (2003, p.2). Retomam a ideia de que a linguagem está sujeita às padronizações sociais que são manifestas intertextualmente e, sendo assim, os Estudos Baseados em Corpus direcionariam a compreensão do ato de traduzir e auxiliariam no ganho de consciência sobre o que está envolvido no processo tradutório.

Segundo Granger (2002), os estudantes podem comparar os resultados de seus trabalhos com os dos profissionais, bem como avaliar as táticas utilizadas e reproduzi-las quando acreditarem ser relevante. Com isso, aprendem a negociar opções e a buscar soluções viáveis. Nesse sentido, os TMs se configuram como instrumentos de mediação e negociação de linguagens e culturas. Os corpora são, pois, maneiras de mensurar o léxico e sua projeção em contextos, equacionam semelhanças e diferenças entre Língua Fonte (LF) e Língua Meta (LM) e mostram a aplicabilidade de novas conceituações ou de omissões, por exemplo.

${ }^{10}$ More recently the corpus-based approach has been developed and applied in translator training where experimental and empirical research go hand in hand with innovative teaching programmes which directly involve students in designing, creating, exploring and exploiting corpora for improving the quality of their translations.

${ }^{11}$ (...) corpus analysis tools will enable students to become better language professionals in a working environment where computational facilities for processing text have the rule rather than the exception (BERNARDINI; STEWART; ZANETTIN, 2003, p.2). 
Sendo assim, a LC auxilia no desenvolvimento das competências tradutórias, de modo que, em termos pragmáticos, os aprendizes precisam ser ensinados a compilar corpora, assim como a usá-los de modo que favoreça seu aprendizado. Para Varantola (2003), esse uso divide-se em dois conjuntos de habilidades: 1) compilação de corpora e 2) uso de informações fornecidas por corpus.

Maia (2003), ao aprofundar os estudos sobre o ensino de Tradução, considera que é um bom método para os estudantes encontrarem e coletarem vocabulários sobre os mais diversos assuntos e, ao mesmo tempo, aprenderem como julgar o estilo, a complexidade e a informação fornecidos por textos distintos.

\subsection{Competências de tradução}

Hurtado (2001, p.395) propõe que o conceito de competências tradutórias estaria diretamente relacionado aos contextos em que os TFs e TMs estão inseridos. A autora sustenta que é importante ao tradutor em formação conhecer as diversas regras de interação, assim como o sentido contextual de cada tipo de texto na LF e na LM. Dessa forma, estas competências tornam-se indispensáveis para que o tradutor possa atingir seus objetivos de modo adequado.

A autora salienta que se entende tal competência como sendo “(...) um conhecimento especializado, integrado por um conjunto de conhecimentos e habilidades, que singulariza o tradutor e o diferencia de outros falantes bilíngues não tradutores" (HURTADO ALBIR, 2005, p.19).

Os membros do PACTE (Processo de Aquisição da Competência Tradutória e Avaliação) salientam algumas atividades com corpora, nesse âmbito, admitem a interação e as trocas de conhecimento entre os estudantes de um grupo, dado que lhes concede a possibilidade de se tornarem independentes no uso de ferramentas e de procurarem por soluções dentro de um conjunto de dados e de atitudes compartilhadas.

A metodologia da LC, associada aos princípios das competências favorece o ensino-aprendizado por meio da experimentação das opções que estão disponíveis, assim como pela avaliação coletiva de TMs e pela decisão da pertinência de respostas 
oferecidas. Sendo assim, estudantes tomam consciência do que podem encontrar nos corpora:

a) Informações mais claras;

b) Trabalho em conjunto;

c) Valores e avaliações de léxicos de especialidade e de terminologias realizados por grupos;

d) Soluções, alterações, decisões e interpretação de conceitos;

e) Reconhecimento de que se aprende muito compartilhando os resultados das escolhas individuais com o resto do grupo;

f) Reflexões sobre a prática e sobre o suporte oferecido pelos Estudos da Tradução;

O aprendiz, ao ser colocado em contato com a formulação de um modelo que lhe permitirá adequar-se aos padrões estabelecidos pela sociedade, bem como pela comunidade dos pares, reconhece e conscientiza-se de que o uso da Linguística de Corpus serve como instrumento e como fonte de dados, os quais, por meio dos glossários, das listas de palavras e das listas de frequência, podem ser uma maneira de buscar adequação às normas que foram estabelecidas em acordos tácitos das culturas envolvidas ou mesmo modificar e propor opções viáveis que poderiam alterar as disposições da conduta compartilhada sobre a prática tradutória.

Além disso, os corpora deste trabalho são exemplos pragmáticos, o que os transforma em material para aumentar a capacidade dos aprendizes de compor suas competências textual, temática e tradutória, entre outras. Aprendizes encontram nos TFs e nos TMs que formam os corpora (paralelos) mediadores para o ato de traduzir.

\subsubsection{As competências tradutórias}

Os estudiosos do PACTE (2011) sugerem que existem seis subcomponentes da competência tradutória, a saber:

1) Competência Comunicativa nas duas línguas, incluindo habilidades linguísticas, discursivas e sociolinguísticas;

2) Competência extralinguística, composta pelo conhecimento de mundo e por conhecimentos especializados; 
3) Competência Instrumental Profissional, composta pelo conhecimento e pelas habilidades relacionados às ferramentas de mercado da profissão;

4) Competência Psico-Fisiológica, definida como uma habilidade de usar todos os tipos de fontes psicomotoras, cognitivas e atitudinais, incluindo habilidades psicomotoras para ler e escrever; habilidades cognitivas (por exemplo: memória, atenção, criatividade e raciocínio lógico); atitudes psicológicas (por exemplo: curiosidade, perseverança, rigor, espírito crítico e autoconfiança);

5) Competência de Transferência, a qual representa uma habilidade para completar o processo de transferência de uma LF para uma LM, ou seja, entender a LF e reexpressá-la no TT, considerando as funções que uma tradução pode assumir, bem como as características do público de chegada;

6) Competência estratégica, que inclui todos os procedimentos conscientes ou inconscientes, coletivos ou individuais, verbais ou não-verbais utilizados para resolver possíveis dificuldades encontradas durante o processo tradutório.

Em estudos subsequentes, contudo, os teóricos eliminam a competência de transferência, substituindo-a pelo conhecimento sobre Tradução (declarativo), ou seja, saberes e habilidades relacionados com o exercício da profissão de tradutor (mercado de trabalho, tarifas, horários, valores éticos).

\section{Material e metodologia de compilação e levantamento das EIs}

Para o desenvolvimento de nossa pesquisa, compilamos os seguintes subcorpora: 1) um subcorpus formado pelas legendas de 111 episódios do seriado Gossip Girl, originalmente produzidos em língua inglesa (total de itens: 7.547.494); 2) um subcorpus formado pelas legendas de 111 episódios do seriado A garota do blog, em língua portuguesa (total de itens: 6.621.981). Ambos os subcorpora foram compilados por meio do site <www.tvsubtitles.net>, o qual disponibiliza legendas de diversos seriados. Nosso subcorpus principal 
de TOs, Gossip Girl, é composto pelas legendas originais em língua inglesa, enquanto o subcorpus principal de TTs, A garota do blog, apresenta as legendas traduzidas para o português, o que nos possibilita analisar a escolha tradutórias apresentadas para as EIs em tela.

Para a extração das palavras-chave, contamos com dois corpora de referência ${ }^{12}$, um em português e outro em inglês. Em português, utilizamos o corpus Lácio-Ref, um corpus aberto e de referência do português contemporâneo do Projeto Lácio-Web, composto de textos em português brasileiro, tendo como característica serem escritos respeitando a norma culta. Este corpus é composto por textos de diversos gêneros, tais como textos científicos, de referência, informativos, jurídicos, prosa, poesia, drama, instrucionais e técnicoadministrativos (ALUÍSIO et. al., 2003).

Já para a língua inglesa, utilizamos o corpus de referência British National Corpus (BNC Sampler), composto por textos originalmente escritos em inglês e desenvolvido pela parceria de membros da Oxford University Press, Longman Group Ltd., Chambers Harrap, Oxford University Computing Services, UCREL - Lancaster University e British Library Research and Development Centre.

A extração das EIs foi realizada com a utilização do programa WordSmith Tools-versão 4.0 (SCOTT, 2004). Tendo por base os dados fornecidos pela ferramenta WordList, selecionamos as cinquenta palavras de maior frequência de ordem substantival e adjetival presentes no subcorpus de LF. Tais informações foram cruzadas com as cinquenta palavras-chave do mesmo subcorpus, elegidas com o uso da ferramenta Keywords. Após o cruzamento, selecionamos os vocábulos que apresentaram reincidência nas duas listas para compor a base de buscas das concordâncias. Por fim, passamos a utilizar a ferramenta Concord à procura de possíveis EIs. A figura 1, a seguir, ilustra o levantamento realizado com o utilitário:

\footnotetext{
${ }^{12}$ Um corpus de referência é formado por textos na mesma língua do corpus de estudo e convenciona-se que seja cinco vezes maior que este.

${ }^{13}$ Os corpora de referência utilizados para o levantamento das palavras de maior chavicidade em nossa pesquisa são comumente utilizados nas investigações das pesquisadoras de forma que sua descrição aparece em outros artigos de sua autoria.
} 
Figura 1: Exemplo de levantamento de EIs baseadas na palavra de busca girl na ferramenta Concord do software WordSmtih Tools.

told me herself that she and Gossip Girl have a history, 211 00:09:02,076

,411 she's working with the real Gossip Girl to take you down. 208 00:08:56,571 vell, I guess I could ask the real Gossip Girl 169 00:06:42,487 - > 00:06:44,027 00:11:18,346 and you can stay Gossip Girl forever. 261 00:11:20,303 $\rightarrow>00: 11$ : number to track down the real Gossip Girl, 258 00:11:09,463 $\rightarrow>00: 11: 12,949$ $: 09: 02,076 \rightarrow 00: 09: 03,221$ so Gossip Girl is probably $21200: 09: 03,222 \rightarrow 00$ : $\rightarrow 00: 06: 21,881$ I bet the real Gossip Girl would help us. $16000: 06: 21,882 \rightarrow$ ,301 You're actually her. You're Gossip Girl. 6 00:00:15,302 - > 00:00:17,695

I want to help you stay on as Gossip Girl. 4 00:00:10,302 $\rightarrow$ 00:00:13,511 | 1 00:00:02,517 $\rightarrow$ 00:00:04,996 Gossip Girl here-- your one and only source 2 mean, we can't let Serena stay Gossip Girl. 153 00:06:06,284 $\rightarrow>00: 06: 07,096$ 00:04:32,991 Serena acting as Gossip Girl. 110 00:04:32,992 $\rightarrow$ 00:04:35,804

Fonte: Elaborada pelas autoras

Após termos empreendido esta primeira etapa da análise, procedemos aos mesmos passos para o subcorpus em LM, com o intuito de encontrar as possíveis opções de tradução para as EIs em língua inglesa ${ }^{14}$.

Elencamos setenta EIs que foram ordenadas em quatro exercícios ou jogos, procurando trabalhar tanto a estrutura linguística de sua composição como o significado e as possibilidades de tradução, focando nas proposições determinadas pelo conceito de competência.

\subsection{Procedimentos para sala de aula}

Ao transformarmos os dados dos subcorpora das legendas Gossip Girls em atividades didáticas, procuramos apresentar, primeiramente, as teorizações e metodologias da Linguística de Corpus

\footnotetext{
${ }^{14}$ É interessante pontuar que tal procedimento foi realizado porque o processo de tradução de legendas permite uma maior variabilidade na LF e na LM no tocante à pontuação e quebras das orações, de modo que, ao utilizarmos a função de alinhamento do software, não obtivemos os mesmos cortes no TO e no TT, tendo sido necessário adotar outra metodologia de busca para as EIs.
} 
e dos Estudos da Tradução baseados em Corpus aos tradutores em formação de forma que pudessem lidar com elementos reais da linguagem e com a composição de EIs de acordo com valores culturais relevantes.

Compusemos um plano de aula que abarcou a temática do seriado, bem como sua relação com outros suportes para a mesma obra, como os romances nos quais foi baseado, os quais foram publicados pela Little, Brown and Company, entre os anos de 2002 e 2007, totalizando 13 livros.

Propomos a discussão sobre o vocabulário nos contextos de partida e de chegada, focando na composição das EIs, de forma que os aprendizes, subsidiados pelos estudos de corpora, pudessem construir suas habilidades, bem como promover associações e reassociações estratégicas.

Ordenamos os dados de análise com o intuito de utilizar os jogos com as EIs observadas nas legendas do seriado como primeiro passo para a conscientização do papel do tradutor ao lidar com tais expressões voltadas ao público jovem e para a futura retradução por parte dos alunos, considerando, a princípio, as escolhas lexicais, a frequência e a chavicidade apresentadas pelos aplicativos do WordSmith Tools.

Compreendemos que as EIs selecionadas dentro da linguagem jovem são parte de um contexto que pode ser utilizado e reutilizado pelos tradutores profissionais, bem como pelos aprendizes de tradução na composição de seus TMs, principalmente com o amparo das ferramentas da LC.

Nesse sentido, os subcorpora trazem à baila uma perspectiva de interação com os TFs e TMs, a qual não apenas elucida possibilidades e estratégias tradutórias, mas também eleva as opções lexicais para que os aprendizes tenham aptidão para desenvolver conhecimentos conceitualizados e criar os enlaces necessários entre as teorizações e as práticas.

Verificamos que quanto maior a noção que os aprendizes recebem em relação às escolhas contidas nos TFs, maior a independência de suas opções em seus TMs na cultura de chegada, visto que passam a observar os aspectos linguísticos e suas vinculações com os elementos sociais presentes nos textos. Além disso, acreditamos que o ensino das competências tradutórias revela a 
ordenação de escolhas amparadas não somente pelo léxico, mas também por valores semânticos e sintáticos. Sendo assim, tencionamos apresentar aos tradutores em formação como as habilidades de ordem pragmática ancoram-se em interpretações teóricas a fim de proporcionar ao profissional saberes e capacidades de conduzir, definir e redefinir sentidos por meio da produção de seus TMs.

Com isso, elaboramos possíveis atividades a serem levadas para as disciplinas de Prática de Tradução, com o objetivo de aumentar os parâmetros dos saberes dos alunos e fornecer materiais para o reconhecimento do impacto das escolhas das EIs, principalmente no que diz respeito ao tema, o qual tem um caráter cotidiano do uso da linguagem.

A seguir, apresentamos o quadro 1, com a estruturação dos assuntos a serem discutidos e das competências abordadas:

Quadro 1: Teorias, conceitos e competências desenvolvidas

\begin{tabular}{|l|ll|}
\hline \multicolumn{1}{|c|}{ Teorias } & \multicolumn{1}{|c|}{ Competências Abordadas } \\
\hline A) Conceitos básicos da Linguística & & \\
de Corpus: & 1) & Competência Extralinguística \\
-corpus paralelo & 2) Competência Instrumental \\
-frequência & & Profissional \\
-chavicidade & 3) Competência de Transferência \\
B) Conceitos básicos dos Estudos da & 4) Competência Estratégica \\
Tradução Baseados em Corpus; & 5) Conhecimentos de Tradução \\
C) Conceitos de Lexicologia: & & \\
-Expressões Idiomáticas & \\
D) O programa WordSmith Tools; & & \\
& \\
\hline
\end{tabular}

Fonte: Elaborado pelas autoras

De acordo com nossa proposição, os estudantes seriam apresentados a valorações teóricas em uma primeira fase, a qual fomentaria habilidades como:

a) Observação da importância da frequência dos itens lexicais tanto na LF quanto na LM;

b) Capacitação para o desenvolvimento de listas de opções de tradução pautadas nas palavras de maior frequência e nas palavras-chave; 
Os estudantes desenvolvem condições para reconhecer o ambiente, as características linguístico-textuais dos TFs e as consequentes adequações para a leitura do público alvo. A partir desses conhecimentos, voltam-se para as práticas e atividades que lhes permitem utilizar as competências adquiridas, assim como reforçá-las e observá-las dentro de uma conjuntura.

Utilizam as ferramentas, metodologias e conceituações apreendidas na fase anterior para reconhecer os elementos do léxico da fala dos jovens de Upper East Side das legendas que poderão traduzir futuramente. $\mathrm{O}$ quadro 2 ilustra as etapas em sala de aula no tocante à formulação das aptidões para a tradução de Gossip Girl.

Quadro 2: Atividades e competências correlatas

\begin{tabular}{|c|c|}
\hline Atividades & Competências abordadas \\
\hline $\begin{array}{l}\text { Aula Expositiva:Gossip Girl } \\
\text { A) A linguagem em Gossip Girl } \\
\text { B) A Constituição das traduções em } \\
\text { Português } \\
\text { C) As EIs mais frequentes em LF }\end{array}$ & $\begin{array}{l}\text { 1) Competência Comunicativa } \\
\text { 2) Competência Extralinguística } \\
\text { 3) Competência Instrumental } \\
\text { Profissional } \\
\text { 4) Competência Estratégica }\end{array}$ \\
\hline $\begin{array}{l}\text { A formação da consciência sobre o valor } \\
\text { cultural presente nas EIs. } \\
\text { Utilização das listas de frequência, bem } \\
\text { como das concordâncias apresentadas pelo } \\
\text { processamento do TF e dos TMs nas } \\
\text { ferramentas do WordSmith Tools. } \\
\text { Busca pelas significações e discussão das } \\
\text { possíveis opções adotadas pelos tradutores } \\
\text { em relação à base do TF. } \\
\text { Realização dos jogos desenvolvidos, com o } \\
\text { intento de proporcionar o reconhecimento } \\
\text { das EIs a posterior atividade de retradução } \\
\text { das legendas. }\end{array}$ & $\begin{array}{l}\text { 1) Competência Comunicativa } \\
\text { 2) Competência Extralinguística } \\
\text { 3) Competência Instrumental } \\
\text { Profissional } \\
\text { 4) Competência Psico-Fisiológica } \\
\text { 5) Competência de Transferência } \\
\text { 6) Competência Estratégica } \\
\text { 7) Conhecimento de Tradução } \\
\text { (declarativo) }\end{array}$ \\
\hline
\end{tabular}

Fonte: Elaborado pelas autoras

Com base no levantamento e nas reflexões realizadas anteriormente, os estudantes passam a utilizar-se dos conhecimentos compartilhados para desenvolver suas competências. O quadro acima 
salienta que o uso das listas de palavras de maior frequência, bem como das palavras-chave e concordâncias pode auxiliar na composição de um conjunto de saberes especializados, auxiliando a formação dos novos profissionais de Tradução.

\section{Análise do corpus paralelo de Gossip Girl como base para o material e instrumental das atividades voltadas aos tradutores em formação}

Nessa etapa de nossa pesquisa, observamos o corpus constituído pelas legendas das cinco temporadas de Gossip Girls e por suas respectivas traduções para o português, como fontes para o desenvolvimento de materiais e atividades formuladas para o ensino das competências tradutórias. Elencamos, a princípio, as palavras mais frequentes no TF e no TM, colocando em destaque as possíveis opções de uso de um conjunto lexical de maior incidência. A seguir, apresentamos as Tabelas 1 e 2, com as frequências das palavras de acordo com a WordList do WordSmith Tools:

Tabela 1: Dez palavras de maior frequência de ordem substantival e adjetival no TF.

\begin{tabular}{c|c}
\hline WORD & FREQUENCY \\
\hline GIRL & 1055 \\
\hline LOVE & 925 \\
\hline GOSSIP & 686 \\
\hline LITTLE & 633 \\
\hline PARTY & 613 \\
\hline NIGHT & 571 \\
\hline FRIENDS & 420 \\
\hline IDEA & 292 \\
\hline PRETTY & 269 \\
\hline MONEY & 145 \\
\hline
\end{tabular}

Fonte: Elaborada pelas autoras 
Tabela 2: Dez palavras de maior frequência de ordem substantival e adjetival no $T M$

\begin{tabular}{c|c}
\hline PALAVRA & FREQUENNCIA \\
\hline VERDADE & 917 \\
\hline TEMPO & 749 \\
\hline CASA & 664 \\
\hline FESTA & 652 \\
\hline CARA & 455 \\
\hline LUGAR & 414 \\
\hline PESSOAS & 409 \\
\hline DEUS & 397 \\
\hline AMIGOS & 356 \\
\hline DINHEIRO & 302 \\
\hline
\end{tabular}

Fonte: Elaborada pelas autoras

As listas de palavras nos textos do corpus de estudo permitem aos aprendizes comparar os empregos e princípios atribuídos aos núcleos vocabulares da série e verificar as alternações de sentidos presentes nas ocorrências entre as diferentes línguas.

Com base nos subcorpora das legendas em inglês e português, é possível observar as aproximações e distanciamentos promovidos pelos tradutores profissionais, como, por exemplo, no uso da palavra money (145) e "dinheiro" (302). A utilização do vocábulo em LM é mais constante que em LF, revelando a possibilidade de diferentes valores atribuídos ao seu conceito, bem como o aumento no grau de importância de seu uso nos contextos do TM.

Sendo assim, os aprendizes de tradução se deparam com a composição de legendas bastante dissociativas, o que favorece a compreensão da formação dos TMs como textos per se, conforme apontado por Baker (1996, 1999, 2000).

As EIs enfatizam essa "independência” dos TMs, uma vez que, nos contextos de Gossip Girls, revelam um padrão do processo tradutório, o qual não segue os mesmos parâmetros de constituição de expressões por meio de combinatórias fixas, permitindo mudanças e reenquadramentos do léxico em LM.

Trazemos, para sala de aula, informações sobre esse conjunto vocabular e comparamos os usos das palavras em LF e em LM, a fim de traçar comparações não somente no que tange as predileções dos 
tradutores, mas também no que diz respeito aos conteúdos que se articulam para TF e TM, respectivamente.

Notamos, por exemplo, as ocorrências de party, vocábulo notoriamente envolto pela ideia de "comemoração" ou "celebração". Em LF, de acordo com The Oxford English Dictionary (1989), party significa "(...) uma ocasião social, geralmente na casa de uma pessoa, em que os convidados comem, bebem, conversam, dançam e se divertem". Além disso, suas ocorrências em combinatórias das legendas originais do seriado apresentam os seguintes contextos:

1) Jenny, you wanna go to that party, you should go.

2) (boy) You know Serena-- she'd never miss a party.

3) What the hell is your problem?! It's a party. Things happen.

4) well,this party would've been the perfect opportunity for you to announce your return, but I guess I'lljust,uh, keep the dress for myself.

5) After the way I came down on you at the party.

Com o intuito de contrastar e ressaltar os usos para os estudantes, levantamos excertos do correspondente presumível em LM, "festa":

1) Eu nunca fui a uma "festa" dessas antes.

2) A Serena, nunca perde uma "festa".

3) Serena e seu homem misterioso apareceram de surpresa na "festa" da Blair.

4) Desculpe, mas tudo deve estar perfeito na "festa" da Eleanor.

5) Te vejo na sua "festa" hoje à noite.

No Novo Dicionário da Língua Portuguesa (FERREIRA, 19,75 295), o conceito de "festa" é descrito como: "1. Reunião alegre para fim de divertimento. 2. O conjunto de cerimônias com que se celebra qualquer acontecimento; solenidade, comemoração (...)".

Nesse sentido, os discentes passam a analisar que os significados dos itens lexicais assumem conteúdos possivelmente mais ou menos amplos nos idiomas envolvidos no processo tradutório, uma vez que "festa", em língua portuguesa, pode representar ainda "festividades" relacionadas a "casamentos" e "celebrações", elementos que, em língua inglesa, são representados por vocábulos próprios, como weddings.A fim de ampliar os conhecimentos e as abordagens 
sobre a importância do uso das palavras dentro dos TFs e dos TMs, apresentamos, a seguir, as Tabelas 3 e 4, com as palavras de maior chavicidade em nossos subcorpora, extraídas com o aplicativo Keywords do programa WordSmith Tools:

Tabela 3: Dez palavras de maior chavicidade de base substantival e adjetival no subcorpus de LF

\begin{tabular}{c|c}
\hline KEYWORDS & KEYNESS \\
\hline GOSSIP & $3,972.89$ \\
\hline GIRLS & $1,893.31$ \\
\hline GUYS & $1,495.37$ \\
\hline LOVE & $1,019.47$ \\
\hline BOYFRIEND & 490.12 \\
\hline CRAZY & 325.77 \\
\hline DATING & 315.37 \\
\hline FRIENDS & 265.86 \\
\hline WEDDING & 256.57 \\
\hline PRETTY & 227.14 \\
\hline
\end{tabular}

Fonte: Elaborada pelas autoras

Tabela 4: Dez palavras de maior chavicidade de base substantival e adjetival no subcorpus de LM

\begin{tabular}{c|c}
\hline PALAVRAS-CHAVE & CHAVICIDADE \\
\hline FESTA & 975.33 \\
\hline FELIZ & 849.73 \\
\hline FAMÍLIA & 557.61 \\
\hline VERDADE & 550.85 \\
\hline IDEIA & 543.03 \\
\hline AMIGA & 469.64 \\
\hline CARA & 456.52 \\
\hline GAROTA & 456.11 \\
\hline VESTIDO & 412.60 \\
\hline NAMORADO & 407.16
\end{tabular}

Fonte: Elaborada pelas autoras

Com o emprego dessas tabelas e listas em aula, o professor media a relação que se estabelece entre os estudantes e o corpus. Os alunos compreendem a importância concedida à chavicidade do vocabulário do TF e sua implicação no TM. Verificam uma 
intercalação de acepções, de modo que as palavras que apresentam similitudes ou analogias ocorrem com maior intensidade: girls $\rightarrow$ "garotas"; guy $\rightarrow$ "cara"; boyfriend $\rightarrow$ "namorado"; e friend $\rightarrow$ "amiga".

Os aprendizes notam que com a pesquisa das palavras-chave é possível obter um número maior de itens do léxico que podem ser entendidos como correspondentes tradutórios. No plano da composição das EIs, conscientizam-se de que pela investigação da chavicidade reconhecem-se os núcleos das EIs. Os alunos, então, verificam procedimentos para composição das estruturas da linguagem com fundamentos estáveis.

Contudo, é pertinente notar que as distinções entre as definições e usos das palavras pode levar a erros interpretativos, principalmente no que tange a elaboração de EIs. Por tal razão, é interessante salientar o cruzamento das informações promovidas pela frequência e pela chavicidade, elevando as categorias das palavras e permitindo que o aprendiz possa, por si só, reconhecer regularidades, bem como promover novas correlações e acepções.

Observamos, por exemplo, a palavra girl; parte considerável das EIs encontradas em nosso trabalho estão pautadas ou ancoradas nesse vocábulo em LF, ao passo que em LM, a principal opção de tradução verificada, "garota" não é a única escolha promovida no TM, permitindo aos aprendizes notarem a solubilidade do processo tradutório e a tendência do tradutor a não atribuir valorações semelhantes aos conjuntos léxicos ainda que estes possam ser considerados como correspondentes diretos entre LF e LM.

Esse fator impulsiona a forma como se dá a aprendizagem das competências tradutórias, uma vez que os aprendizes ganham "autonomia" para fazerem uso delas no entendimento das estruturas linguístico-culturais dos TFs e na reordenação de suas preferências, bem como na consciência de seu papel como produtores de significados.

Partindo dessas explanações, elencamos, no quadro 3, as EIs identificadas tendo como parâmetro o cruzamento entre a frequência e a chavicidade das palavras de nosso corpus de estudo.

${ }^{15} \mathrm{O}$ conceito de autonomia, em nosso trabalho, está incluído na proposta de conhecimento das competências e capacidade de gerenciamento das escolhas tradutórias. 
Quadro 3: Setenta EIs selecionadas no subcorpus das legendas de Gossip Girls

\begin{tabular}{|c|c|}
\hline TF & TM \\
\hline $\begin{array}{l}\text { GIRL } \\
\text { 1) And Constance's Bad-Girl-Turned- } \\
\text { Good. } \\
\text { 2) Sorry to disappoint, but this won't be it- } \\
\text { girls gone wild. } \\
\text { 3) How handy is it that society girls are } \\
\text { wafer-thin? } \\
\text { 4) I've dated a lot of topflight girls, and } \\
\text { she always sends them running. } \\
\text { 5) Blair says we can't get "a"- list girls } \\
\text { because our show is the same time as Marc } \\
\text { Jacobs. }\end{array}$ & $\begin{array}{l}\text { 1) E a aluna malvada de Constance } \\
\text { que virou boazinha. } \\
\text { 2) Trecho omitido da tradução } \\
\text { 3) É bom que garotas da sociedade } \\
\text { sejam magras. } \\
\text { 4) Eu já namorei muitas garotas } \\
\text { interessantes, e ela sempre dava um } \\
\text { jeito de despachá-las. } \\
\text { 5) Blair diz que não conseguiremos } \\
\text { as melhores garotas porque nosso } \\
\text { desfile é ao mesmo tempo que o de } \\
\text { Marc Jacobs. }\end{array}$ \\
\hline $\begin{array}{l}\text { LOVE } \\
\text { 6) Yeah, well, she doesn't strike me as the } \\
\text { love-at-first-sight type, so just give it some } \\
\text { time. }\end{array}$ & $\begin{array}{l}\text { 6) Ela não me parece do tipo Amor à } \\
\text { primeira vista, então dê um tempo. }\end{array}$ \\
\hline $\begin{array}{l}\text { GOSSIP } \\
\text { 7) It is your destiny to be gossip-worthy; }\end{array}$ & 7) É seu destino ser alvo de fofocas. \\
\hline $\begin{array}{l}\text { LITTLE } \\
\text { 8) Well, I don't know why you're suddenly } \\
\text { so interested in that sad little shut-in, but } \\
\text { here you go; } \\
\text { 9) You little-black-booked the pain away? } \\
\text { 10) We should get used to little run-ins like } \\
\text { these. }\end{array}$ & $\begin{array}{l}\text { 8) Não sei por que você está tão } \\
\text { interessada nessa pequena criatura, } \\
\text { mas aqui está. } \\
\text { 9) - Usou a agenda? } \\
\text { 10) Mesmo se nãofosse, devemos nos } \\
\text { acostumar com encontros. }\end{array}$ \\
\hline $\begin{array}{l}\text { PARTY } \\
\text { 11) A celebratory dinner sounds like a good } \\
\text { after-party. } \\
\text { 12) Throw-a-party-good news. Your dad? } \\
\text { Look, can we actually talk later? } \\
\text { 13) No. Dan is more of a corner-of-the- } \\
\text { party guy. }\end{array}$ & $\begin{array}{l}\text { 11) Um jantar de comemoração me } \\
\text { parece uma boa after-party. } \\
\text { 12) Meu pai provavelmente vai dar } \\
\text { uma festa pra boa notícia. } \\
\text { 13) Não. Dan é mais um cara que fica } \\
\text { no canto da festa. }\end{array}$ \\
\hline $\begin{array}{l}\text { NIGHT } \\
\text { 14) It was a feeding frenzy last night. } \\
\text { 15) That's--that's two nights in a row. }\end{array}$ & $\begin{array}{l}\text { 14) Foi um furor ontem à noite. } \\
\text { 15) São duas noites seguidas. }\end{array}$ \\
\hline $\begin{array}{l}\text { FRIEND-S } \\
\text { 16) But I just wanted to do something to say, } \\
\text { hello, we're more than friends with } \\
\text { benefits. }\end{array}$ & $\begin{array}{l}\text { 16) Só queria fazer algo para mostrar } \\
\text { que somos mais que amigos com } \\
\text { benefícios. }\end{array}$ \\
\hline $\begin{array}{l}\text { FRIENDSHIP } \\
\text { 17) We're not really in a friendship groove }\end{array}$ & 17) Não é um clima de amizade. \\
\hline
\end{tabular}




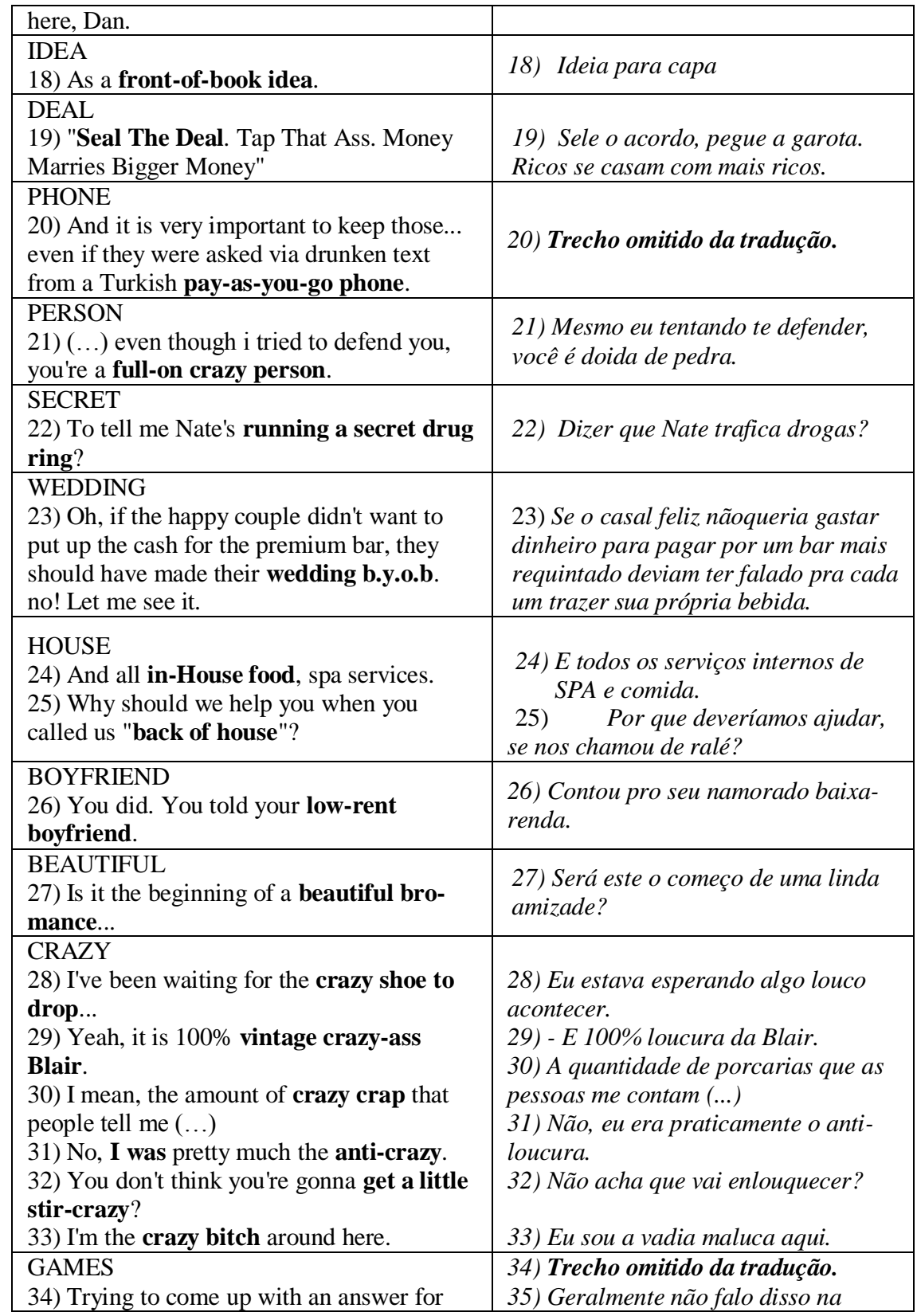


Talita Serpa; Ariane Caldas; Paula Pinto

\begin{tabular}{|c|c|}
\hline $\begin{array}{l}\text { the Dean's parlor game? } \\
\text { 35) Well, it's usually not a part of my "a" } \\
\text { game pillow talk. }\end{array}$ & cama. \\
\hline $\begin{array}{l}\text { DATING } \\
\text { 36) And thank me for forgiving you of your } \\
\text { dating faux pas. } \\
\text { 37) With real honest-to-goodness dating. } \\
\text { 38) It's a huge dating taboo. }\end{array}$ & $\begin{array}{l}\text { 36) E me agradecer por perdoá-lo de } \\
\text { seus passos em falso. } \\
\text { 37) O velho e bom namoro. } \\
\text { 38) É um grande tabu dos encontros. }\end{array}$ \\
\hline $\begin{array}{l}\text { HEART } \\
\text { 39) Spotted at the palace hotel: s. and } \\
\text { b.having a heart-to-heart. } \\
\text { 40) "The vengeance of hell boils in my } \\
\text { heart." } \\
\text { 41) Our first hear-To-Heart talk in--In } \\
\text { ever. }\end{array}$ & $\begin{array}{l}\text { 39) Vistas no Hotel Palace } S . \text { e B. } \\
\text { tendo uma conversa de irmã para } \\
\text { irmã. } \\
\text { 40) A vingança do inferno ferve no } \\
\text { meu coração. } \\
\text { 41) Eu e minha filha tivemos nossa } \\
\text { primeira conversa sincera. }\end{array}$ \\
\hline $\begin{array}{l}\text { SEX } \\
\text { 42) A same-sex kiss hasn't caused this much } \\
\text { controversy. } \\
\text { 43) We're stuck in this meaningless mind- } \\
\text { blowing sex loop. } \\
\text { 44) It's just your ordinary, run-of-the-mill } \\
\text { ex sex, fueled by the most common of } \\
\text { aphrodisiacs... }\end{array}$ & $\begin{array}{l}\text { 42) Um beijo gay não causa tanta } \\
\text { controvérsia. } \\
\text { 43) Estamos presos a esse loop sexual } \\
\text { sem sentido. } \\
\text { 44) É só sexo normal, ativado pelos } \\
\text { afrodisíacos mais comuns... }\end{array}$ \\
\hline $\begin{array}{l}\text { HONEST } \\
\text { 45) Get two people in a room willing to be } \\
\text { balls-out honest? }\end{array}$ & $\begin{array}{l}\text { 45) Colocar duas pessoas numa sala } \\
\text { dispostas a serem honestas? }\end{array}$ \\
\hline $\begin{array}{l}\text { BITCH } \\
\text { 46) I was just bitch-slapped by Bridget } \\
\text { Jones. } \\
\text { 47) I'll be sure to check that out on } \\
\text { bitchslappedagain.com later. } \\
\text { 48) Hot bitch from Chapin. } \\
\text { 49) I'd say, let's get the bitch. } \\
\text { 50) I know i acted like a complete and total } \\
\text { raging bitch last year. }\end{array}$ & $\begin{array}{l}\text { 46) Meu deus. Acabei de ser estapeada } \\
\text { pela Bridget Jones. } \\
\text { 47) Vou checar no 'vadia-bate-de- } \\
\text { novo.com'. } \\
\text { 48) Vadia gostosa da Chapin. } \\
\text { 49) Eu diria: Vamos pegar a vadia. } \\
\text { 50) Olha... (suspiro) eu sei que agi } \\
\text { como uma total e completamente vadia } \\
\text { ano passado. }\end{array}$ \\
\hline $\begin{array}{l}\text { HAND } \\
\text { 51) Who wears my hand-me-downs, and } \\
\text { she blabbed to Nate. }\end{array}$ & $\begin{array}{l}\text { 51) Que usa minhas roupas usadas, } e \\
\text { ela dedurou ao Nate. }\end{array}$ \\
\hline $\begin{array}{l}\text { SISTER } \\
\text { 52) And he told his social-climbing sister } \\
\text {... }\end{array}$ & $\begin{array}{l}\text { 52) E ele contou à irmã em ascensão } \\
\text { social... }\end{array}$ \\
\hline $\begin{array}{l}\text { PISSY } \\
\text { 53) I know. It's much easier to be pissy on }\end{array}$ & 53) - É fácil ficar puto no ichat. \\
\hline
\end{tabular}




\begin{tabular}{|c|c|}
\hline ic & \\
\hline $\begin{array}{l}\text { TEXT } \\
\text { 54) You know, with your Sushi pun text } \\
\text { flirting and all that. } \\
\text { 55) I got caught in a text flurry with } \\
\text { Dorota. I'm sorry. }\end{array}$ & $\begin{array}{l}\text { 54) Com seus trocadilhos e flertes por } \\
\text { SMS e tudo mais. } \\
\text { 55) Me perdi trocando SMS com a } \\
\text { Dorota. Desculpe. }\end{array}$ \\
\hline $\begin{array}{l}\text { BOSS } \\
\text { 56) As long as the pit boss doesn't make you } \\
\text { for counting cards. }\end{array}$ & $\begin{array}{l}\text { 56) Desde que o rei do buraco lhe faça } \\
\text { contar as cartas. }\end{array}$ \\
\hline $\begin{array}{l}\text { HAPPY } 65 \\
57 \text { ) To burst your happy bubble, but I'm not } \\
\text { giving up. } \\
\text { 58) And a bowl of ice cream, she's happy as } \\
\text { a clam. }\end{array}$ & $\begin{array}{l}\text { 57) (...) em desmanchar sua bolha de } \\
\text { felicidade, mas não vou desistir. } \\
\text { 58) (...) e uma tigela de sorvete, ela } \\
\text { ficará feliz. }\end{array}$ \\
\hline $\begin{array}{l}\text { GLAD } \\
\text { 59) In the second grade, I saw our gym } \\
\text { teacher giving Laverne Glazer's mom the } \\
\text { glad eye. }\end{array}$ & $\begin{array}{l}\text { 59) Na segunda série, vi nosso } \\
\text { professor de Ed. Física dar uma } \\
\text { secada na mãe da Laverne Glazer. }\end{array}$ \\
\hline $\begin{array}{l}\text { ASS } \\
\text { 60) I need to kick her well-rounded ass. } \\
\text { 61) Babblin' at your ass, from dusk till } \\
\text { dawn. } \\
\text { 62) Sings this kick-ass aria, "der holle rache } \\
\text { kocht in meinem herzen," } \\
\text { 63) Well, I certainly don't have to worry } \\
\text { about your weak-ass jumper, do I? } \\
\text { 64) Do they have a word in Polish for "pain } \\
\text { in the ass"? } \\
\text { 65) Oh! You are ass-backwards crushing } \\
\text { on Blair Waldorf! } \\
\text { 66) I'm saddled with the mutt, he can freeze } \\
\text { his ass, too. } \\
\text { 67) "Seal The Deal. Tap That Ass. Money } \\
\text { Marries Bigger Money" }\end{array}$ & $\begin{array}{l}\text { 60) Preciso fazer mais que ela. } \\
\text { 61) Enchendo seu saco sem parar, do } \\
\text { anoitecer ao amanhecer. } \\
62) \text { (...) canta essa melodia } \\
\text { impressionante, "der holle rache kocht } \\
\text { in meinem herzen," } \\
\text { 63) Com certeza não terei que me } \\
\text { preocupar com seu suéter delicado, } \\
\text { não? } \\
\text { 64) Tem uma palavra em polonês para } \\
\text { "chatice"? } \\
\text { 65) Estás fora de ti e apaixonado pela } \\
\text { Blair Waldorf! } \\
\text { 66) Já que estou sobrecarregado por } \\
\text { culpa dele,vou dar trabalho para ele. } \\
\text { 67) Sele o acordo, pegue a garota. } \\
\text { Ricos se casam com mais ricos. }\end{array}$ \\
\hline $\begin{array}{l}\text { SLEEPOVER } \\
\text { 68) With your little teenybopper sleepover. }\end{array}$ & $\begin{array}{l}\text { 68) Achei que conseguiu isso com a } \\
\text { sua festinha de pijama. }\end{array}$ \\
\hline $\begin{array}{l}\text { MAD } \\
\text { 69) Not only am I manly and rugged, but I } \\
\text { also have mad browsing skills. }\end{array}$ & $\begin{array}{l}\text { 69) - Não apenas sou másculo e rude, } \\
\text { como também tenho ótimas } \\
\text { habilidades de busca. }\end{array}$ \\
\hline $\begin{array}{l}\text { PRENUP } \\
\text { 70) Mmm. Two more prenup shots, please. }\end{array}$ & 70) Maisduas, por favor. \\
\hline
\end{tabular}

Fonte: Elaborado pelas autoras 
A elaboração de atividades envolvendo as EIs e suas combinatórias foi realizada com embasamento na utilização da ferramenta Concord. A exposição dos dados, conforme a disposição acima, favorece a apreciação das preferências tradutórias por parte dos aprendizes, os quais passam a explorar a conjuntura das associações, encontrando, primeiramente, os modelos em LF, os quais podem ser elencados conforme o quadro 4 , a seguir:

Quadro 4: Modelos de formação das EIs em Gossip Girls

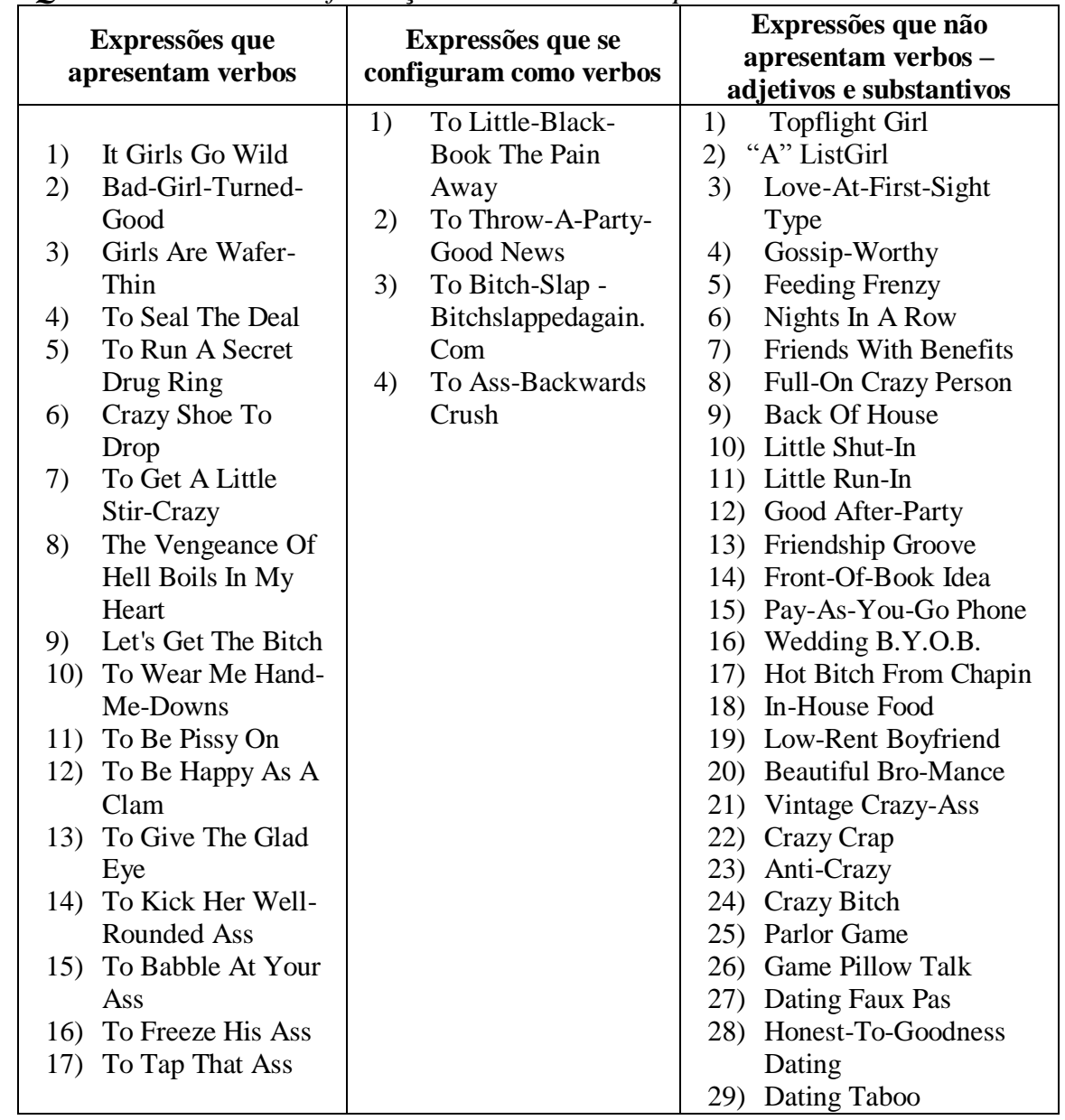




\begin{tabular}{|c|c|c|}
\hline & & $\begin{array}{ll}\text { 30) } & \text { Heart-To-Heart } \\
\text { 31) } & \text { Hear-To-Heart Talk In } \\
\text { 32) } & \text { Same-Sex Kiss } \\
\text { 33) } \text { Mind-Blowing Sex } \\
\text { Loop } \\
\text { 34) } \text { Run-Of-The-Mill Ex } \\
\text { Sex } \\
\text { 35) Balls-Out Honest } \\
\text { 36) } \text { Total Raging Bitch } \\
\text { 37) } \text { Social-Climbing Sister } \\
\text { 38) Sushi Pun Text Flirting } \\
\text { 39) } \text { A Text Flurry } \\
\text { 40) } & \text { Happy Bubble } \\
\text { 41) } & \text { Kick-Ass Aria } \\
\text { 42) Weak-Ass Jumper } \\
\text { 43) Pain In The Ass } \\
\text { 44) Teenybopper Sleepover } \\
\text { 45) Mad Browsing Skills } \\
\text { 46) Prenup Shots }\end{array}$ \\
\hline
\end{tabular}

Fonte: Elaborado pelas autoras

As EIs, em sua maioria, são pautadas em adjetivações ou classificações e determinações de situações, pessoas ou ambientes. Tendem a revelar, com maior reincidência, um vocabulário voltado para as personagens jovens e que se fundamenta em combinações de substantivos e adjetivos para elaborar novos contextos e significações, como em: text flurry, game pillow talk, parlor game e happy bubble.

Dessa forma, os alunos iniciam um processo de reconhecimento das palavras separadamente e, em seguida, conseguem distinguir as associações em dadas conjunturas.

O maior núcleo dessas associações encontra-se entre as EIs que não apresentam verbos, ou seja, que não determinam ações. Descobrimos 46 (quarenta e seis) exemplos de organizações dessas EIs, contudo, existem também 17 (dezessete) expressões voltadas para atuações e afazeres, por exemplo: to freeze his ass, to give the glad eye, to be pissy one, to babble at that ass.

Por fim, existem ainda EIs que representam os próprios verbos, contabilizando apenas quatro ocorrências entre as palavras de maior frequência e de maior chavicidade em nosso corpus, as quais podem ser trazidas à baila durante as discussões entre os tradutores em formação. 
No âmbito das opções e estratégias tradutórias, é possível verificar que existe uma categorização ou um conjunto de aplicações também reincidentes, entre as quais se encontram: a) a explicitação ou exposição dos sentidos das EIs sem o uso de outras expressões na LM; e b) a omissão dos contextos em que são mencionadas.

Os aprendizes reconhecem as formas como os tradutores realizam os procedimentos, observando os contextos como um todo e, em seguida, notam as possibilidades diretamente vinculadas às EIs. Com isso, verificam os usos, e conseguem perceber, de maneira mais destacada, as ações tradutórias e a forma como esses agentes articulam a linguagem, dando maior ou menor privilégio ao sentido ou à forma.

No caso das EIs, os alunos podem compreender que o valor atribuído a elas em LF não foi mantido em LM, ou mesmo que, em língua portuguesa, o seu uso pode ser reduzido no gênero textual abordado em nosso corpus.

Com o auxílio e mediação da LC e do professor, os tradutores aprendizes notam que existe certa frequência em determinadas condutas quando os tradutores fazem uso de suas competências, de modo que elas acabam por serem utilizadas em conjunto e sem que se tenha plena consciência desta prática.

As EIs são, pois, como uma forma de destacar determinados comportamentos e permitir que possam ser explorados, seguidos ou rechaçados de maneira aclarada e consciente. $\mathrm{O}$ fato de trabalharem elementos da cultura popular e do falar dos jovens em LF, principalmente, ressalta a necessidade de se conseguir formular padrões semelhantes caso o tradutor se depare com um conjunto léxico semelhante.

Por outro, lado, o fato de não haver esse uso em LM ressalta pelo menos três possíveis leituras. A primeira seria a de que o subcorpus do TF apresenta uma maior incidência de EIs, comprovando que a língua inglesa apresenta esse tipo de combinatória linguística com maior repetição, sendo assim, seria necessário ao aprendiz atentar para esse tipo de realização e também para os contextos em que ocorre.

A segunda estaria vinculada ao fato de que, talvez, em língua portuguesa, as EIs de um núcleo lexical compartilhado entre jovens sejam menos frequentes, levando os tradutores a optarem por outras concordâncias nos TMs. 
Em um terceiro momento poderíamos dizer que as EIs em língua portuguesa são também comuns entre adolescentes e pessoas mais jovens, contudo, os tradutores podem não possuir conhecimento sobre elas ou as EIs podem não ser correspondentes em LF e LM, levando os tradutores a outras estratégias.

Assim sendo, se os tradutores não conhecem as EIs correspondentes, um trabalho com corpus poderia levá-los a adquirir tal conhecimento, além de ampliar seus saberes, de forma a permitir que os aprendizes, em um trabalho tradutório futuro, possam realizar as traduções com maior fluidez da linguagem utilizada.

Com as atividades promovidas no tópico seguinte, tencionamos explorar a capacidade de os tradutores em formação distinguirem as EIs por seus conceitos e poderem ou aceitar as práticas dos tradutores profissionais ou utilizar da apreensão de suas competências para tornarem-se tradutores conscientes de suas escolhas, modificando os TMs.

\section{As atividades preparadas}

Para trabalharmos a compreensão das EIs levantadas por meio da análise do nosso corpus paralelo, optamos por desenvolver quatro diferentes tipos de atividades, a saber: um caça-palavras, um conjunto de palavras-cruzadas, um scrabble de IEs e um jogo da memória.

Para a atividade de caça-palavras, utilizamos cinco EIs em nossa proposta, salientando que outros exemplos poderiam ter sido trazidos à discussão. As possíveis traduções das expressões são apresentadas aos alunos em LM, considerando as aulas prévias e as elaborações das interpretações verificadas em classe.

A proposta do jogo é fazer com que os estudantes busquem as EIs correspondentes em nosso corpus de estudo, por meio das linhas de concordância. Esta atividade permite aos professores conduzir uma reflexão sobre a relação entre a forma e o conteúdo de LF e LM por meio das EIs, procurando explicitar que essas construções são, na maioria das vezes, fixas, permitindo pouca ou nenhuma variação, como vimos nas definições de Xatara (1994). No entanto, ao promover o processo tradutório dessas formações, os tradutores podem optar por se valer de suas competências comunicativa e extralinguística a fim de 
adaptar a linguagem do TM para o contexto da cultura de chegada, a qual, conforme mencionamos anteriormente, pode não fazer uso de combinatórias lexicais que se enquadrem na forma de EIs e que sejam correspondentes dos elementos encontrados no TF. A seguir, apresentamos o caça-palavras ${ }^{16}$ :

Figura 2: Caça-palavra de EIs

\begin{tabular}{|c|c|c|c|c|c|c|c|c|c|c|c|c|c|c|c|c|c|c|}
\hline \multicolumn{19}{|c|}{ WORD SEARCH } \\
\hline R & 0 & $\mathrm{H}$ & $\mathrm{T}$ & $\mathrm{U}$ & $F$ & 0 & I I & $x$ & $\mathrm{~N}$ & $\mathrm{~T}$ & $\mathrm{~K}$ & $\mathrm{~s}$ & A & $\mathrm{T}$ & $\mathrm{J}$ & M & $\mathrm{H}$ & 0 \\
\hline E & $\mathrm{C}$ & $R$ & M & $\mathrm{N}$ & $\mathrm{K}$ & $\mathrm{N}$ & $\mathrm{W} R$ & $\mathrm{P}$ & $\mathrm{C}$ & A & $\mathrm{U}$ & $\mathrm{N}$ & $\mathrm{N}$ & $\mathrm{J}$ & $\mathrm{s}$ & $Q$ & $\mathrm{~s}$ & $Y$ \\
\hline $\mathrm{N}$ & $R$ & $\mathrm{H}$ & $W$ & $\mathrm{x}$ & $\mathrm{T}$ & $\mathrm{W}$ & W E & $T$ & $\mathrm{U}$ & $z$ & $\mathrm{~J}$ & $\mathrm{~s}$ & $\mathrm{~s}$ & M & $\mathrm{H}$ & $\mathrm{F}$ & F & P \\
\hline 0 & z & $\mathrm{V}$ & 0 & G & $I$ & A & Q I & $B$ & M & $\mathrm{V}$ & $\mathrm{V}$ & $\mathrm{P}$ & $\mathrm{K}$ & $\mathrm{U}$ & M & $\mathrm{V}$ & $\mathrm{W}$ & 0 \\
\hline $\mathrm{H}$ & A & $Q$ & $\mathrm{~s}$ & I & $\mathrm{U}$ & M & $\mathrm{D} U$ & $\mathrm{z}$ & $\mathrm{E}$ & I & A & $\mathrm{D}$ & $\mathrm{Y}$ & $\mathrm{K}$ & G & B & A & P \\
\hline P & $\mathrm{S}$ & $\mathrm{N}$ & $\mathrm{V}$ & $Q$ & $\mathrm{x}$ & $\mathrm{V}$ & $S 0$ & $\mathrm{~T}$ & 0 & $\mathrm{~N}$ & A & $Y$ & A & $I$ & $\mathrm{U}$ & $\mathrm{N}$ & $Q$ & $I$ \\
\hline 0 & B & I & $\mathrm{x}$ & $\mathrm{z}$ & B & P & E J & U U & $\mathrm{x}$ & $\mathrm{T}$ & $\mathrm{s}$ & $\mathrm{S}$ & $E$ & A & $\mathrm{S}$ & $\mathrm{T}$ & $W$ & z \\
\hline G & $\mathrm{A}$ & $\mathrm{U}$ & $R$ & $Q$ & $\mathrm{~T}$ & $\mathrm{~N}$ & $\mathrm{PC}$ & $\mathrm{G}$ & $\mathrm{N}$ & A & $\mathrm{S}$ & P & $\mathrm{x}$ & $T$ & B & $\mathrm{s}$ & $\mathrm{U}$ & D \\
\hline $\mathrm{U}$ & I & $Q$ & $\mathrm{~K}$ & $\mathrm{U}$ & $D$ & $\mathrm{~W}$ & A $\mathrm{H}$ & $E$ & $\mathrm{~N}$ & G & $\mathrm{H}$ & D & $\mathrm{W}$ & $w$ & $\mathrm{M}$ & A & $E$ & $Q$ \\
\hline 0 & $G$ & P & $\mathrm{N}$ & $Y$ & $\mathrm{~s}$ & $R$ & I $\mathrm{B}$ & 30 & $\mathrm{E}$ & $\mathrm{E}$ & $\mathrm{s}$ & M & $E$ & 0 & $R$ & P & $\mathrm{T}$ & $R$ \\
\hline$Y$ & $\mathrm{~T}$ & $\mathrm{~J}$ & $I$ & 0 & $\mathrm{Y}$ & $\mathrm{T}$ & $\mathrm{N} X$ & $\mathrm{~W}$ & 0 & C & $\mathrm{K}$ & $\mathrm{D}$ & B & $I$ & A & $\mathrm{x}$ & $\mathrm{T}$ & $I$ \\
\hline $\mathrm{S}$ & $R$ & $\mathrm{~K}$ & $\mathrm{~N}$ & $W$ & $\mathrm{~N}$ & $\mathrm{U}$ & I $\mathrm{E}$ & $P$ & $I$ & $\mathrm{R}$ & $\mathrm{K}$ & $\mathrm{N}$ & $\mathrm{N}$ & $I$ & $z$ & $\mathrm{U}$ & P & $G$ \\
\hline A & $\mathrm{C}$ & $E$ & P & $P$ & $\mathrm{~V}$ & $\mathrm{~J}$ & $\begin{array}{lll}N & \mathrm{Z}\end{array}$ & $\mathrm{C}$ & $Q$ & A & $\mathrm{T}$ & $\mathrm{J}$ & 0 & $I$ & $\mathrm{~J}$ & A & $I$ & $T$ \\
\hline$Y$ & A & $\mathrm{W}$ & $\mathrm{K}$ & $Q$ & $\mathrm{~T}$ & I & $T R$ & $z$ & $\mathrm{x}$ & z & $Q$ & $\mathrm{~J}$ & $\mathrm{~N}$ & P & $\mathrm{M}$ & $F$ & $\mathrm{H}$ & $Y$ \\
\hline A & $\mathrm{G}$ & $G$ & $\mathrm{U}$ & $\mathrm{T}$ & $P$ & I & $\mathrm{H} \quad \mathrm{R}$ & $R$ & $\mathbf{T}$ & $Y$ & $\mathrm{x}$ & $\mathrm{T}$ & $F$ & $E$ & $G$ & $\mathrm{G}$ & $W$ & D \\
\hline P & B & $\mathrm{V}$ & $\mathrm{V}$ & $\mathrm{K}$ & $\mathrm{S}$ & $\mathrm{T}$ & E $H$ & $\mathrm{P}$ & $I$ & A & $\mathrm{x}$ & $\mathrm{S}$ & M & $\mathrm{M}$ & $I$ & $\mathrm{~N}$ & M & C \\
\hline$R$ & A & $\mathrm{U}$ & I & $\mathrm{J}$ & $G$ & U & $A U$ & J $R$ & A & $\mathrm{S}$ & 0 & $R$ & $\mathrm{x}$ & A & $E$ & $I$ & A & C \\
\hline $\mathrm{K}$ & $\mathrm{N}$ & $\mathrm{x}$ & P & $\mathrm{x}$ & P & $\mathrm{U}$ & $S \mathrm{~J}$ & $Q$ & $Y$ & $\mathrm{~S}$ & $\mathrm{~T}$ & A & $\mathrm{S}$ & $G$ & $\mathrm{~N}$ & $\mathrm{~T}$ & D & $\mathrm{J}$ \\
\hline $\mathrm{x}$ & $\mathrm{W}$ & $R$ & $\mathrm{~T}$ & $\mathrm{~N}$ & $\mathrm{E}$ & I & $S \mathrm{~K}$ & $\mathrm{G}$ & $I$ & $\mathrm{~N}$ & $G$ & A & $R$ & $\mathrm{~V}$ & 0 & A & $R$ & $\mathrm{~W}$ \\
\hline I & I & $\mathrm{N}$ & $G$ & A & B & I & $Y B$ & 80 & $G$ & $F$ & C & P & $\mathrm{V}$ & $\mathrm{C}$ & & & & $\mathrm{U}$ \\
\hline \multicolumn{19}{|c|}{$\begin{array}{l}\text { 1) Celular pré-pago } \\
\text { 2) Conversa depois do sexo } \\
\text { 3) Escapadas ou pequenas traições } \\
\text { 4) Pé no saco }\end{array}$} \\
\hline
\end{tabular}

Fonte: Elaborada pelas autoras

${ }^{16}$ Elaborado no website:

http://www.atividadeseducativas.com.br/index.php?criarcacapalavras 
Por meio dessa atividade, há um desvencilhamento do que é trazido pelo subcorpus em LM e a recomposição das EIs com o intuito de buscar composições que, embora não se categorizem como indecomponíveis ou cristalizadas, possam remeter a um conjunto léxico correspondente, ou seja, ao linguajar dos jovens no ambiente de circulação do seriado, entre adolescentes brasileiros.

Notamos, por exemplo, as seguintes correspondências:

Quadro 5: Variações possíveis para a tradução das EIs do jogo

\begin{tabular}{|c|c|c|}
\hline TF & TM & $\begin{array}{c}\text { Possível adequação } \\
\text { desenvolvida no jogo }\end{array}$ \\
\hline Game Pillow Talk & Falo disso na cama & $\begin{array}{c}\text { Conversa depois do } \\
\text { Sexo }{ }^{17}\end{array}$ \\
\hline Pain In The Ass & Chatice & Pé no Saco \\
\hline CrazyBitch & Vadia Louca & Doida Varrida \\
\hline
\end{tabular}

Fonte: Elaborado pelas autoras

Com o uso das competências desenvolvidas, os estudantes podem buscar por distintos artifícios da linguagem e reconhecer componentes variados do núcleo léxico com o qual estão lidando. Com seus conhecimentos sobre o ato tradutório, podem utilizar-se dos dados apresentados pelos professores, pelos corpora e, a partir deles, constituir seus próprios arcabouços e explicitações.

Da mesma forma que no caça-palavras, durante o uso do jogo de palavras-cruzadas ${ }^{18}$, os estudantes encontram EIs (no caso foram 15 exemplificações) pautando-se nos conhecimentos de tradução que desenvolvem em sala. Os alunos são instigados a preencherem os espaços verticais e horizontais indicados na legenda da atividade com as formas corretas das EIs em LF.

${ }^{17}$ Essas opções de tradução foram elaboradas com base em nossas discussões e análises, buscando aproximar o universo do TM daquele verificado no TF.

${ }^{18}$ Elaborado no website:

http://www.atividadeseducativas.com.br/index.php?criarcacapalavras 
Figura 3: Palavras-Cruzadas de Eis

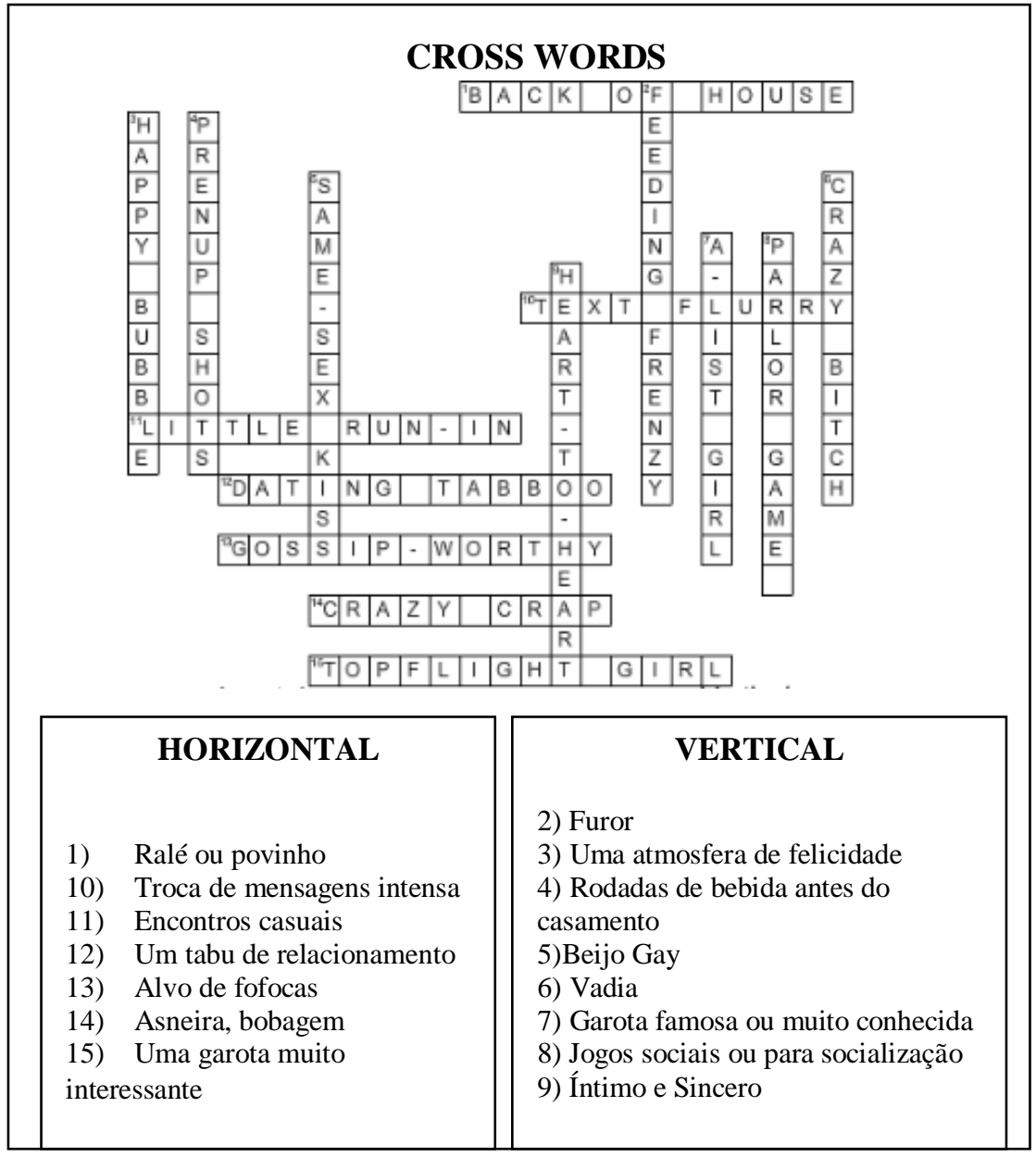

Fonte: Elaborado pelas autoras

Com a apresentação dos itens teóricos relacionados à LC, bem como com amparo dos conceitos de Lexicologia e dos Estudos da Tradução Baseados em Corpus, a realização dessa atividade recebe mais atenção dos aprendizes, uma vez que tomam consciência da importância de se reconhecer os arquétipos e as agregações entre as palavras. 
Além disso, podem balancear a relação entre os itens lexicais, permitindo que se combinem ou não na confecção de EIs na LM. Em alguns dos casos, como em crazy bitch, crazy crap, back of the house e feeding frenzy, encontram correspondentes em palavras ou vocábulos, como "vadia", "asneira", "ralé" e "furor", de modo que as preferências de tradução também variam dentro do linguajar adolescente, indo da língua formal para os dizeres de um determinado grupo social.

O corpus de Gossip Girl, ao receber o status de material didático e fornecer EIs para o exercício de palavras cruzadas, também adiciona aos saberes dos tradutores em formação a probabilidade de observar a estrutura de integração entre as palavras para a formulação de expressões. Com isso, ganham autonomia para produzirem suas combinações e promoverem os conhecimentos de ambos os idiomas, assim como das culturas envolvidas.

Para a elaboração da terceira atividade elencamos um total de dez EIs que foram embaralhadas de modo que os alunos devam recolocá-las em seu formato inicial.

Figura 4: Scrabble de Eis

\section{SCRABBLE DE IES}

HAND - TO - DOWNS - ME - WEAR - ME

BITCH - LETS - THE - GET

IN - HELL - OF - VENGEANCE - THE - BOILS - HEART - MY

STIR - A - GET - LITTLE - CRAZY - TO

SHOE - TO - CRAZY -DROP

A - RING - DRUG - TO - SECRET - RUN

DEAL - TO - THE - SEAL

WAFER - GIRLS - THIN - ARE

GOOD - BAD - TURNED - GIRL

WILD - GIRLS - GO - IT

Fonte: Elaborada pelas autoras 
O uso das EIs permite aos professores trabalharem com o fator ordenação das palavras em contexto. Notamos que durante o exercício de observação dos TMs com suporte no corpus paralelo, bem como nas listas de palavras mais frequentes, na chavicidade e nas concordâncias, os alunos podem compor, gradualmente, o conhecimento sobre a importância de se verificar as palavras e suas constituições, isoladamente e em conjunção com outras, notando as diferenças e as similitudes da utilização dos vocábulos quando se unem ou quando permanecem separados.

Os estudantes formulam, principalmente, sua competência comunicativa, pois somam os valores dos significados das palavras nas EIs e fora delas e reconhecem sua autonomia para fazer essa transição de sentidos.

No Scrabble the EIs ressalta-se a necessidade de haver uma fixidez da forma, pelo menos em LF, com base no subcorpus do TF, considerando, de modo particular, as expressões que utilizam verbos e que trazem para o ambiente da obra ações que também tem a ver com fazeres de um núcleo jovem e "descolado".

Por fim, no jogo da memória, trabalhamos com um total de quatro pares de EIs em LF e em LM. Nesta atividade, os alunos são levados a formarem os pares corretos dos correspondentes das EIs nos dois idiomas, conforme visto na Figura 5.

Assim, os alunos desvendam o amplo universo de possibilidades de um processo tradutório e reconhecem as suas competências para verificar as diferenças das línguas e das culturas. Com o destaque dado ás EIs há ainda a possibilidade de enquadramento dentro de ordenações textuais, revelando verbalizações, subjetivações e adjetivações que podem ser de difícil compreensão para o tradutor, incorrendo em equívocos interpretativos e traduções que se afastam do conteúdo dos TFs. 
Figura 5: Jogo da Memória dos Eis

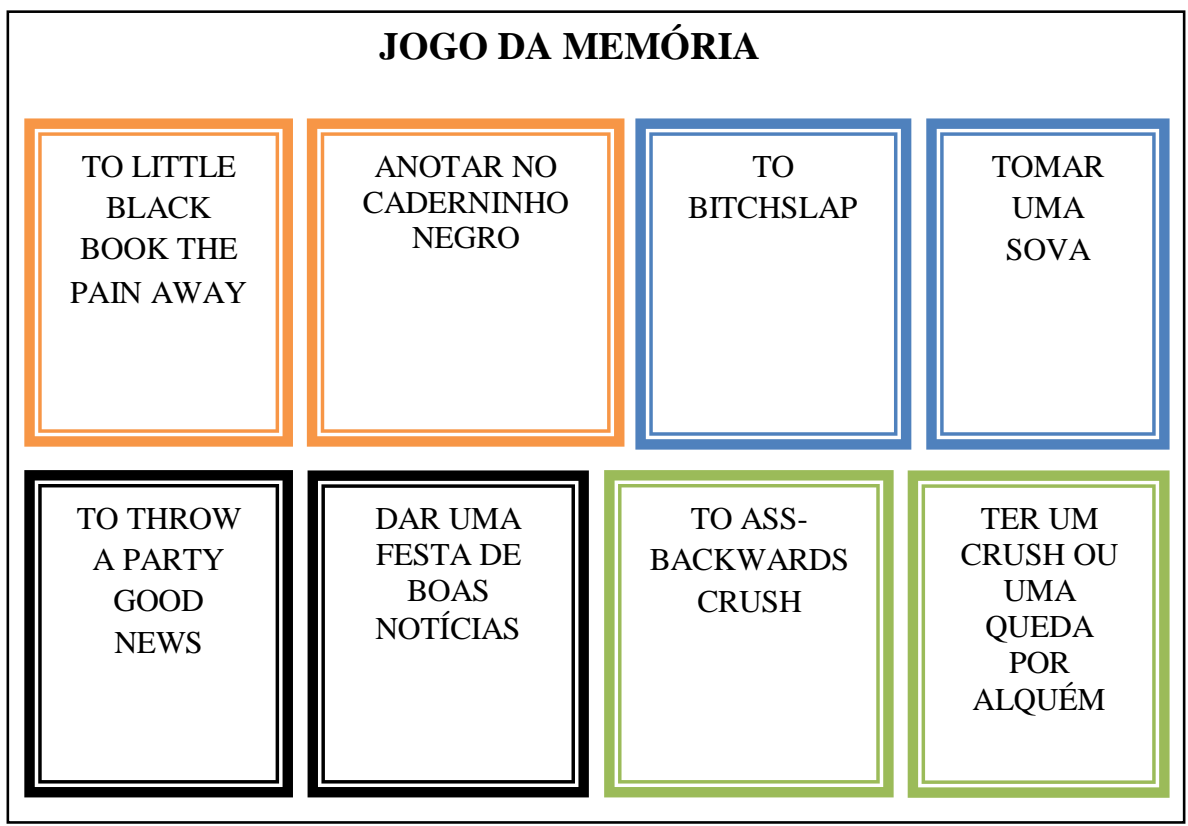

Fonte: Elaborada pelas autoras

O jogo da memória também traz à tona a questão de se reconhecer as EIs como uniformizadas, de modo que não sofrem alterações muito amplas na sua fixação, levando, novamente, os aprendizes a esforçar-se por reconhecer, não necessariamente a imutabilidade da LF e da LM, mas sim a existência de determinadas combinações que são comuns aos falantes e que, por consequência, fazem parte de uma vivência e de um uso da língua, revelando mais que simplesmente a necessidade de manter a estrutura das EIs, mas sim a importância que, naquele momento, naquele contexto, aquela EI assume. Há uma expressividade que perpassa o valor do texto e se dirige para o corriqueiro, pra o habitual de ambas as sociedades envolvidas.

É dessa forma que as atividades previstas alcançam a composição das competências de âmbito psico-fisiológico e comunicativo, além de favorecerem os saberes no próprio arcabouço da Tradução. 


\section{Considerações finais}

A relação interdisciplinar estabelecida entre as teorizações de Hurtado Albir (2000, 2001, 2005) e do grupo PACTE (2011) para o ensino de competências tradutórias e os arcabouços dos Estudos da Tradução Baseados em Corpus (BAKER, 1993, 1995, 1996, 2000), da Linguística de Corpus (BERBER SARDINHA, 2004) e da Lexicologia (XATARA, 1994, 1998), permite-nos verificar a associação com o uso de corpora para o trabalho com tradutores em formação (BERBER SARDINHA, 2010).

Em nossa pesquisa, consideramos que o corpus e a sua depreensão em elementos lexicais de maior frequência e de maior chavicidade ressaltam, na conjuntura da aprendizagem da Tradução, fatores das línguas que não seriam facilmente explorados se não fosse por meio dessa ferramenta e das teorizações a ela associadas.

A dissociação das palavras do texto, com o uso da WordList e da Keywords do WordSmith Tools e sua análise em blocos com o auxílio da ferramenta Concord mostram que o recorte do TF e do TM favorece a verificação minuciosa dos grupos lexicais, permitindo que os alunos percebam a importância das correlações entre as palavras, entre as suas combinatórias e entre essas agregações e o contexto geral.

A frequência das palavras equaciona-se para que o professor possa realizar procedimentos de mediação entre a linguagem e os usos, de forma que os estudantes tenham a possibilidade de ponderar sobre a elegibilidade de um vocábulo em LM para uma tradução plausível de um conteúdo em LM.

Ao levarmos os corpora e as teorizações da LC para a sala de aula, por meio das atividades com as EIs, consideramos haver a preocupação com o papel do tradutor como produtor de conhecimento, como elaborador de combinatórias e como modificador de significados.

Os aprendizes, a nosso ver, desenvolvem, com auxílio das bases em corpora, os saberes voltados a uma habilidade para participar de construções de sentidos para os TTs, de forma que os indivíduos (estudantes) ganharam consciência do papel de suas inclinações na composição das expressões. 
Por meio da inter-relação entre distintas teorias, os estudantes respondem aos estímulos de um modelo de exploração pedagógica que se ampara nas potencialidades dos corpora levados para o ambiente universitário. As congruências com as considerações educacionais beneficiaram o estruturamento de uma Pedagogia da Tradução Baseada em Corpus.

Os procedimentos adotados compõem a verificação das preferências não somente linguísticas, mas também culturais, formando modelos de ensino.

Sendo assim, seguindo estas proposições, acreditamos ter podido promover a ordenação dos conhecimentos e capacitações competentes às performances tradutórias, correlacionando as estratégias e ações recorrentes a premissas e padrões conceituais no campo da formação de EIs.

\section{Referências}

BAKER, M. Corpora in translation studies: an overview and some suggestions for future research. Target, v. 7, n. 2, p. 223-243, 1995.

Corpora in translation studies: the challenges that lie ahead. In: SOMERS, H. (Ed.) Terminology, LSP and translation studies in language enginnering: in honour of Juan C. Sager. Amesterdã: John Benjamins, 1996. p. 177-186.

. Linguística e estudos culturais: paradigmas complementares ou antagônicos nos estudos da Tradução? In: MARTINS, M. A. P. (Org.) Tradução e multidisciplinaridade. Rio de Janeiro: Lucena,1999. p. 15-34.

Towards a methodology for investigating the style of literary translation. Target, Amsterdã, V. 12, n. 2, p. 241-266, 2000.

BARBOSA, M. A. Considerações sobre a estrutura e funções da obra lexicográfica: metodologia, tecnologia e condições de produção. In: 
COLÓQUIO DE LEXICOLOGIA E LEXICOGRAFIA. Anais... Lisboa, Universidade Nova de Lisboa, 1990, 229-241.

BARROS, L. A. Curso básico de terminologia. São Paulo: USP, 2004.

BERBER SARDINHA, A. P. Linguística de corpus. São Paulo: Manole, 2004.

- Como usar a Linguística de Corpus no Ensino de Língua Estrangeira: por uma Linguística de Corpus Educacional brasileira. In: TAGNIN, S. E. O.; VIANA, V. Corpora no ensino de línguas estrangeiras. São Paulo: HUB Editorial, 2010. p. 293-348.

BIBER, D. et al. Corpus Linguistics: investigating language structure and use. Cambridge: Cambridge University Press, 1998.

CAMARGO, D. C. Padrões de estilo de tradutores: um estudo de semelhanças e diferenças em corpora de traduções literárias, especializadas e juramentadas. 2005. 512f. Tese (Livre-Docência em Estudos da Tradução) Instituto de Biociências, Letras e Ciências Exatas, UNESP, São José do Rio Preto, 2005.

. Metodologia de pesquisa em tradução e linguística de corpus. Coleção Brochuras, v.1. São Paulo: Cultura Acadêmica/São José do Rio Preto: Laboratório Editorial, 2007.

DUBOIS, J. et al. Dicionário de linguística. Trad. Frederico Pessoa de Barros et al. São Paulo: Cultrix, 2001.

EVEN-ZOHAR, I. The position of translated literature within the literary polisystem. In: HOLMES, J. et al(Ed.). Literature and translation. Leuven: ACCO, 1978. p. 117-127 [Versão revisada em VENUTI, L. (Ed.). The translation studies reader. London/New York: Routledge, 2000, p. 199-204].

FERREIRA, A. B. H. Novo dicionário da língua portuguesa. 3. ed. Rio de Janeiro: Nova Fronteira, 1975. 
O Universo teen de Gossip Girl em Língua Portuguesa...

GRANGER, S. A bird's-eye view of learner corpus research. Computer learner corpora, second language acquisition and foreign language teaching, p. 3-33, 2002.

GOSSIP GIRL. Disponível em: <http://www.tvsubtitles.net>. Acesso em: 01 jul. 2014.

HURTADO ALBIR, A. Un nuevo enfoque de la didáctica de la traducción: metodología y diseño curricular. In: Les langues étrangères dans l'Europe de l'acte unique. Belaterra : ICE, Universitat Autònoma de Barcelona, 1993.

. Didáctica de la traduccíon. In: Le BEL, E. (Ed.) Le masque et la plume: traducir: reflexiones, experiencias y prácticas. Sevilha: Universidade de Sevilha, 1995.

- (dir.) Enseñar a traducir: metodología en la formación de traductores e intérpretes. Madrid: Edelsa, 1999.

- La competencia traductora y su adquisición: un modelo holístico y dinámico. Perspectives: Studies in Translatology, v. 7, n. 2, p. 177-188, 2000.

. Traducción y traductología: introducción a la traductología. Madrid: Cátedra, 2001.

A aquisição da competência tradutória: aspectos teóricos e didáticos. In: ALVES,F. et al. (Orgs.) Competência em tradução: cognição e discurso. Belo Horizonte: Editora UFMG, 2005. p. 19-57.

LAVIOSA, S. Corpus-based translation studies: theory, findings, applications. Amsterdã/Atlanta: Rodopi, 2002.

MAIA, B. The pedagogical and linguistic research implications of the GC to on-line parallel and comparable corpora. In: ALMEIDA, J. J. (Ed.). Corpora paralelos: aplicações e algoritmos associados. Braga: Univ. Minho, 2003. p. 31-32. 
PACTE. Results of the validation of the PACTE Translation Competence Model: translation problems and translation competence. In: ALVSTAD, HILD, TISELIUS (Eds.) Methods and strategies of process research: integrative approaches in translation studies. Amsterdam: John Benjamins, 2011. p. 317-343.

. Results of the validation of the PACTE Translation Competence Model: translation project and dynamic translation index. In: O'BRIEN (Ed.) Cognitive explorations of translation. London and New York: Continuum Studies in Translation, 2014. p. 30-53.

. Results of PACTE's experimental research on the acquisition of translation competence: the acquisition of declarative and procedural knowledge in translation: the dynamic translation index. Translation Spaces, v. 4, n. 1, p. 29-53, 2015.

SCOTT, M., WordSmith Tools: version 4. Oxford: Oxford University Press. 2004.

SIMPSON, J.; WEINER, E. S.C. Oxford English Dictionary online. Oxford: Clarendon Press. Retrieved March, v. 6, 1989

TOGNINI-BONELLI, E. Corpus linguistics at work. Amsterdã/Atlanta, GA: John Benjamins, 2001.

TOURY, G. The nature and role of norms in literary translation. In: HOLMES, J.; et al. (Ed.). Literature and translation. Leuven: ACCO, 1978. p. 83-100. [Versão revisada em VENUTI, L. (Ed.). The translation studies reader. London/New York: Routledge, 2000, p. 205 -218].

VARANTOLA, K. Translators and disposable corpora. In: Zanettin, F; Bernardini, S.; Stewart, D. (Eds.). Corpora in translator education, Manchester: St. Jerome, 2003. p. 55-70.

VERCEZE, R. M. N. Gêneros textuais no processo de ensinoaprendizagem. Estudos Lingüísticos, v 37, n.2, 2008. 
O Universo teen de Gossip Girl em Língua Portuguesa...

XATARA, C. M. Tipologia das expressões idiomáticas. ALFA: Revista de Linguística, v. 42, n. 1, p. 169-176, 1998.

XATARA, C. M.; RIVA, H. C.; RIOS, T. H. C. As expressões idiomáticas de matriz comparativa. São Paulo: UNESP, 1994.

ZANETTIN, F.; et al. Corpora in translator education. Manchester: St. Jerome, 2003.

Recebido em: 21/11/2016

Aceito em: 16/12/2016

Title: The teen universe in Brazilian Portuguese translation for Gossip

Girl: a proposal of teaching translational competences 